\title{
Diffusion coefficient through the blood-aqueous barrier using a standard protocol
}

Jaap van Best, Jose Benitez del Castillo, Michael Diestelhorst, Bernard Heintz, Eugenio Leite, Louis-Filip Liesenborghs, Rainer Schalnus on behalf of European Concerted Action on Ocular Fluorometry

\begin{abstract}
Aims/Background-Comparison of the diffusion coefficient through the bloodaqueous barrier of healthy volunteers measured in different cities with identical fluorophotometers using a standardised protocol.
\end{abstract}

Methods-Healthy volunteers aged between 20 and 70 years were studied in seven European cities. The fluorescein concentration in the anterior segment of each eye was measured with a commercial scanning fluorophotometer 30 and 40 minutes after intravenous fluorescein. The decay of non-protein bound fluorescein concentration in blood plasma was determined with the use of three blood samples taken at 7,15 , and 55 minutes after injection. The diffusion coefficient through the blood-aqueous barrier was calculated from the ratio between the fluorescein concentration in the anterior chamber and the time integral of nonprotein bound fluorescein concentration in plasma using specially developed software.

Results-The mean values of the diffusion coefficient (SD) $\left(\times 10^{-4} \mathrm{~min}^{-1}\right)$ were 4.76 $(1 \cdot 51)(n=20$, Brussels), $5 \cdot 48$ (2.33) $(n=17$, Coimbra), 3.47 (2.09) ( $n=12$, Cologne), 6.09 (2.77) (n=21, Frankfurt), 3.85 (1.59) (n=11, Ghent), $4.99(1.69)(n=23$, Leiden), and $4.87(1.05) \quad(n=20$, Madrid $)$. The values between centres were similar (Kruskal-Wallis test $p>0.05$ ) except for Cologne and Frankfurt $(p=0 \cdot 013)$. No differences were found when repeating measurements (four centres, interval time 1-8 months, Wilcoxon paired test p $>0.39)$.

Conclusion-The diffusion coefficients had similar values and standard deviations. The concerted action demonstrated the usefulness of a standardised protocol. (Brf Ophthalmol 1996; 80: 356-362)

Quantitative measurements of the bloodaqueous barrier (BAB) permeability or of the diffusion coefficient through the $B A B\left(k_{d}\right)$ in humans have been performed previously with fluorophotometry after cataract surgery and intraocular lens implantation ${ }^{1-8}$ and to study the effects of topical drugs. ${ }^{9-11}$ The measurements were also performed in diabetic patients, ${ }^{10-16}$ in uveitis patients, ${ }^{17} 18$ and in patients with retinal vein occlusion ${ }^{19}$ or retinal detachment. $^{20}$

Various methods and protocols for the quantification of the permeability of the $\mathrm{BAB}$ were used which could result in different outcomes. The easier method was to use the concentration of fluorescein in the anterior chamber (in $\mathrm{ng} / \mathrm{ml}$ ), measured at a fixed time $(30,45$, or 60 minutes) after intravenous injection of a fixed amount of fluorescein (7 or $14 \mathrm{mg} / \mathrm{kg}$ body weight). $571012171820 \mathrm{An}$ extra spread (more than $30 \%$ ) in the values obtained can be expected since the amount of permeated fluorescein strongly depends on plasma fluorescein clearance, binding to plasma proteins, and to some extent on glucuronidation of fluorescein. ${ }^{21-24}$ Another method is to compare the fluorescein concentration in the anterior chamber of a treated eye with that before treatment or with that of the untreated fellow eye. ${ }^{2911}$ In the first case changes in the clearance of plasma fluorescein can still play a role and in the latter case a consensual reaction cannot be excluded. ${ }^{2}$ Still another way is to correct the fluorescein concentration in the anterior chamber by dividing its value by the fluorescein concentration in blood plasma. ${ }^{3}$ This can only be done at a fixed time after injection since plasma fluorescein decays with time while anterior chamber fluorescein increases. Errors can still occur because the shape of the plasma fluorescein decay curves are not necessarily identical. Other investigators use the mean fluorescence value at one or three fixed locations in the anterior chamber and divide the value by the non-protein bound fluorescein time integral ${ }^{4619}$ or define an apparent transfer coefficient after oral fluorescein. ${ }^{1}$

The diffusion coefficient for fluorescein $\left(\mathrm{k}_{\mathrm{d}}\right.$ in $\mathrm{min}^{-1}$ or $\left.\mathrm{h}^{-1}\right)$ can be obtained by dividing the peak fluorescein concentration in the anterior chamber at a certain time by the corresponding time integral of non-protein bound fluorescein (NPBF) in plasma. The value of $k_{d}$ was proved not to depend on plasma fluorescein, time after fluorescein injection, or amount of fluorescein injected and has been used by 
several investigators. ${ }^{13}$ 23-28 Glucuronidation was shown to play only a minor role provided measurements took place within 1 hour after intravenous injection. ${ }^{23}$ The permeability of the $\mathrm{BAB}$ (in $\mathrm{nm} / \mathrm{s}$ ) can also be calculated ${ }^{23}$ but this value is questionable since it depends strongly on the fluorescein permeating area of the iris which is difficult to calculate because of its wrinkled state.

Therefore, a protocol for the fluorophotometric determination of $k_{d}$ in a standardised way was drawn up in detail in cooperation with experts in several countries of the European Community (Belgium, Germany, Portugal, Spain, and the Netherlands).${ }^{29}$ Oral administration of fluorescein was not used since this would mainly result in protein bound or glucuronidated fluorescein in blood. The evaluation of the $\mathrm{BAB}$ function would become less sensitive because protein bound fluorescein molecules $(M W>50000)$ pass the BAB less easily than NPBF $(M W=376)$ while glucuronidated NPBF molecules $(M W=508)$ have a $30 \times$ lower fluorescence quantum efficiency. ${ }^{23} 30$ Furthermore, the evaluation would become inaccurate as a result of the different excitation and emission spectra of bound fluorescein and the interindividual and time dependent variation in fluorescein binding. ${ }^{21} 23$ The NPBF concentration in blood plasma was determined with the use of three blood samples obtained from an intravenous catheter. Fingertip samples were not appropriate because the determination of $\mathrm{NPBF}$ in a sample requires at least $2-3 \mathrm{ml}$ of blood.

All $k_{d}$ values were determined according to this standardised protocol in healthy subjects at different centres in order to verify the feasibility and usefulness of the procedures.

\section{Materials and methods}

\section{CALCULATION OF THE DIFFUSION \\ COEFFICIENT $k_{d}$}

After intravenous injection, fluorescein reaches the anterior chamber mainly via the iris vessels and leaves via the aqueous humour flow and cornea.

The increase of fluorescein concentration in the anterior chamber can be written as ${ }^{24}$ :

$$
\begin{array}{r}
\frac{d C a}{d t}=k_{d} \cdot\left(C_{p}-C_{a}\right)+k_{f} \cdot\left(C_{h}-C_{a}\right)+\underset{a . c a}{ } \cdot\left(C_{d} / r_{c a}-C_{a}\right) \\
\left(k^{-3} m^{-3} s^{-1}\right)
\end{array}
$$

where $C_{a}, C_{p}, C_{h}$, and $C_{c}$ are the non-protein bound fluorescein concentrations (NPBF in kg $\mathrm{m}^{-3}$ ) in the anterior chamber, blood plasma, pupillary aqueous, and cornea respectively; $k_{d}$ is the diffusion coefficient of NPBF from plasma (in the iris vessels) into the anterior chamber (in $\mathrm{s}^{-1}$ ); $\mathrm{k}_{\mathrm{f}}$ is the loss coefficient due to aqueous outflow (in $\mathrm{s}^{-1}$ ); $\mathrm{k}_{\mathrm{a} \text {.ca }}$ is the aqueous to cornea diffusion coefficient referred to the anterior chamber volume (in $\mathrm{s}^{-1}$ ); and $\mathrm{r}_{\mathrm{ca}}$ is the correction factor for steady state concentration difference between cornea and anterior chamber, as a result of bound fluorescein in the cornea $\left(r_{c a}=1 \cdot 6\right){ }^{31}$
After integration of both sides of equation (1) from the average time of the first passage of fluorescein through the iris vessels $\left(t_{d}\right)$ up to the time of measurement $\left(t_{m}\right)$ one obtains for the diffusion coefficient $\mathrm{k}_{\mathrm{d}}$ :

$$
k_{d}\left(t_{m}\right)=K \frac{C_{a}\left(t_{m}\right)}{I_{p}\left(t_{m}\right)}
$$

where $\mathrm{K}$ depends on $\mathrm{k}_{\mathrm{f}}, \mathrm{k}_{\mathrm{a} . \mathrm{ca}}, \mathrm{r}_{\mathrm{ca}}, \mathrm{C}_{\mathrm{p}}(\mathrm{t}), \mathrm{C}_{\mathrm{a}}(\mathrm{t})$, $C_{h}(t), C_{c}(t), t_{d}$, and $t_{m}$ and its value is 1.0 (SD $0 \cdot 1)$ provided $10<t_{m}<70$ minutes ${ }^{23} ; C_{a}\left(t_{m}\right)$ is the fluorescein concentration in the anterior chamber at time $t_{m}$ after injection; and $I_{p}\left(t_{m}\right)$ is the time integral of the NPBF in plasma.

The decay of NPBF in blood plasma can be approximated by a power of time function ${ }^{21}$ :

$$
\mathrm{C}_{\mathrm{p}}(\mathrm{t})=\alpha \cdot \mathrm{t}^{-\beta}
$$$$
\left(\mathrm{kg} \mathrm{m}^{-3}\right)
$$

where $\alpha$ and $\beta$ are constants depending on subject and amount of fluorescein injected. Integrating $\mathrm{C}_{\mathrm{p}}(\mathrm{t})$ from the time of first appearance in the eye $\left(t_{d}\right)$ up to the time of measurement $\left(t_{m}\right)$ yields the time integral $I_{p}\left(t_{m}\right)$ :

$$
I_{p}\left(t_{m}\right)=\int_{t_{d}}^{t_{m}} C_{p}(\tau) d \tau=\frac{\alpha}{(1-\beta)} \cdot\left(t_{m}^{1-\beta}-t_{d}^{1-\beta}\right)\left(k g ~ s ~ m^{-3}\right)
$$

The diffusion coefficient $k_{d}$ is calculated using equation (2) wherein the value of $C_{p}\left(t_{m}\right)$ corresponds to the peak value of fluorescein concentration in the anterior chamber and the value of the time integral is calculated using equation (4). $\mathrm{K}$ is assumed to be 1.0 and $t_{d}=54$ seconds. ${ }^{29}$ The values of $\alpha$ and $\beta$ are obtained by a power regression procedure to the NPBF concentration values in blood plasma samples taken at 7,15 , and 55 minutes after injection.

\section{SUBJECTS}

\section{Healthy controls}

The purpose was to recruit 20 healthy controls in each centre, four recruited from each of the following age categories: 20-29, 30-39, $40-49,50-59$, and $60-69$ years. The criteria were: no medication at present except oral contraceptives, no contact lens wear, visual acuity of 10/10, normal aspect of all corneal layers on slit-lamp examination, no corneal lesions.

\section{Trial group}

The purpose was to recruit 15 diabetic patients. The criteria were: age category 20-39 years, insulin dependent diabetes mellitus (IDDM), 8 years diabetes duration or more, normal blood pressure (WHO: diastolic pressure $<95 \mathrm{~mm} \mathrm{Hg}$ ), retinopathy according to Wisconsin 2-3-4 grading, no nephropathy.

The studies have been conducted according to the principles established in the Declaration of Helsinki and were approved by local medical ethics committees. All subjects gave their informed consent after explanation of the nature of the procedures. 


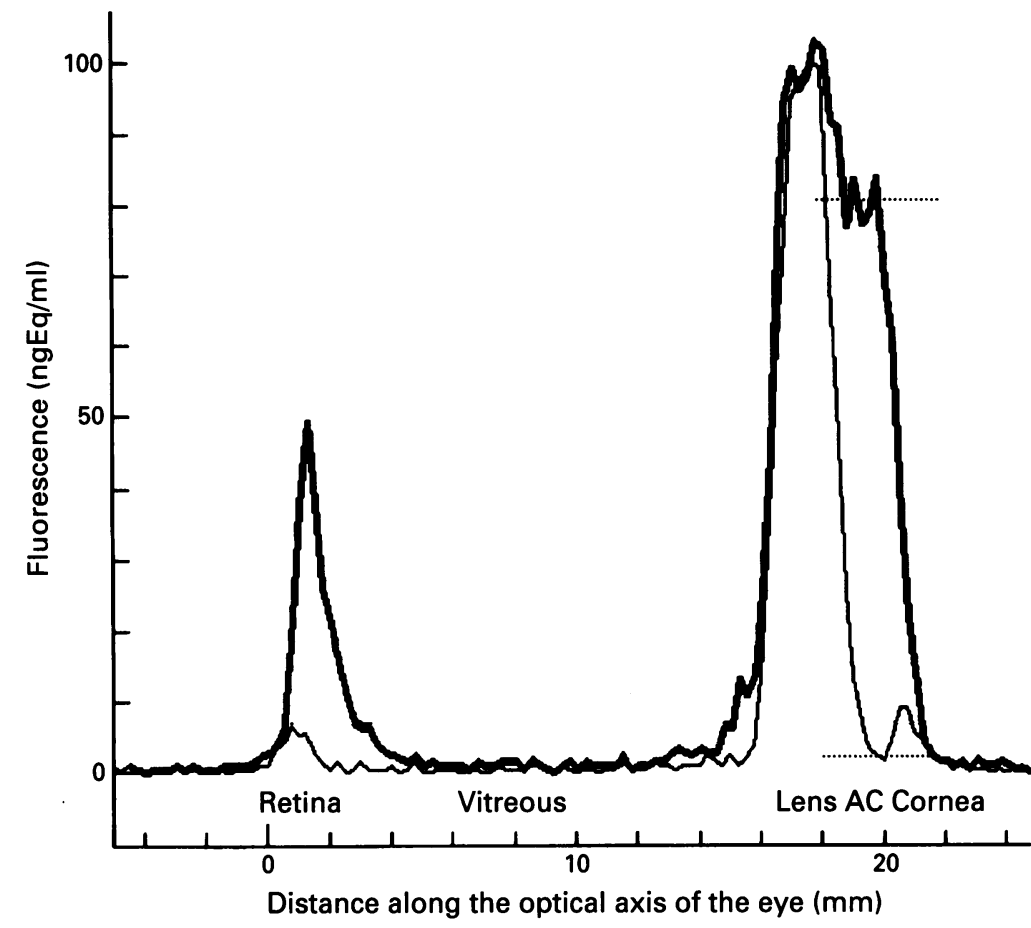

Figure 1 Example of fluorescence scans along the optical axis of the eye made before intravenous injection of fluorescein (prescan, thin curve) and 40 minutes thereafter (measurement scan, thick curve). The fluorescence values are expressed in ng equivalent fluorescein/ml. The distance along the optical axis is calculated from the number of scan steps per mm. The horizontal broken lines represent the fluorescence values at the anterior chamber. The instrumental vitreous lens was used.

\section{MEASUREMENT PROCEDURE}

(1) The fluorophotometer (Fluorotron Master, Coherent Radiation Inc, Palo Alto, CA, USA) was turned on at least 20 minutes before measurements. Stability was checked with a fluorescence standard (Zeiss fluorescence reference F-53, Zeiss, Germany).

(2) Slit-lamp examination of both eyes was performed by an ophthalmologist without the use of fluorescein since this could interfere with the measurements.

(3) Four fluorophotometric (pre-)scans (scan duration about 15 seconds) were performed in each eye for determination of the autofluorescence values of the anterior chamber and the cornea (Fig 1, thin curve, 4 scan steps $/ \mathrm{mm}, 100 \mathrm{~ms}$ gate time). The scans were registered on disk.

(4) Disodium fluorescein was injected intravenously into an antecubital vein through an indwelling Teflon catheter (about $14 \mathrm{mg} / \mathrm{kg}$ body weight, given as $10 \%$ or $20 \%$ solution at an injection rate of about $10 \mathrm{ml}$ per $12 \mathrm{sec}$ onds). The time of injection was noted. After injection of fluorescein $10 \mathrm{ml}$ of dilute heparin solution was injected through the catheter. Injection was performed with the patient seated. Fundus photography was permitted provided blood sampling or fluorophotometry was not interfered with.

(5) Blood samples were collected from an intravenous catheter into evacuated tubes approximately 7,15 , and 55 minutes after injection. Three blood samples were taken at each sampling time; the first one (at least $15 \mathrm{ml}$ ) was discarded and the following two samples (5-10 ml each) were taken in two separated EDTA tubes (Vacutainer, BectonDickinson). The time of each blood sampling was noted. The catheter was washed after each sampling by injection of $2-5 \mathrm{ml}$ of dilute heparin solution.

(6) Two fluorophotometric scans of each eye were performed alternately at about 30 and 40 minutes after fluorescein injection (Fig 1, thick curve). The time of each scan was noted.

(7) Slit-lamp examination of both eyes was performed by the same ophthalmologist, now with the use of fluorescein. Any irregularity was registered. IOP could be determined.

If possible, all measurements were repeated 1 to 8 months after the first series in order to check reproducibility.

\section{PRACTICAL CONSIDERATIONS}

(1) The first blood samples must be taken between 6 and 8 minutes after fluorescein injection since otherwise the calculation of the time integral of the NPBF in plasma will not be reliable.

(2) Intravenous injection of fluorescein can also be performed directly in one arm and two samples of $3 \mathrm{ml}$ each can be taken at 7,15 , and 55 minutes after injection by means of a syringe from the contralateral arm vein.

(3) Fluorescein angiography can be performed between the fluorophotometric measurements provided it does not interfere with the timing of the first plasma sample. ${ }^{15}$

(4) Simultaneous measurements of the $B A B$ diffusion coefficient and the blood-retinal barrier permeability can be performed provided the short (vitreous) fluorophotometer lens is used and a mydriatic agent is instilled after point (2) of the previous section. ${ }^{15}$ The same instrumental lens should be used for eye and plasma scans. Note that a mydriatic agent can alter the blood flow in the iris and grossly change its geometry. However, the functional area of the barrier will remain relatively unchanged, which results in unchanged values of $k_{d}$. A pilot study in healthy controls and diabetic patients in one of the centres (Leiden) revealed a slightly decreased value of $k_{d}$ (at most $20 \%$ ) when excessive amounts of mydriatic agents were applied.

\section{DATA PROCESSING (OFF LINE)}

(1) Each blood sample was centrifuged (5 minutes at $3000 \mathrm{rpm}$ ). The supernatant was ultrafiltrated for 5 minutes at $3000 \mathrm{rpm}$ by means of an ultrafiltration system (Amicon MPS-1 with YMT membranes 40420; Amicon Corp, Danvers, MA, USA) at an angle of $45^{\circ}$ and at a temperature of $30^{\circ} \mathrm{C}$. The ultrafiltrate was diluted $40 \times$ in phosphate buffer at $\mathrm{pH} 7 \cdot 4$. The fluorescein concentration of the latter dilution was measured in a cuvette in front of the fluorophotometer and the NPBF concentration of the sample was calculated.

(2) A power of time regression procedure was applied to the plasma NPBF values and the corresponding sampling times (determination of $\alpha$ and $\beta$ in equation (3); Fig 2).

(3) The mean anterior chamber autofluorescence value of each eye was determined from the prescans (Fig 1). 


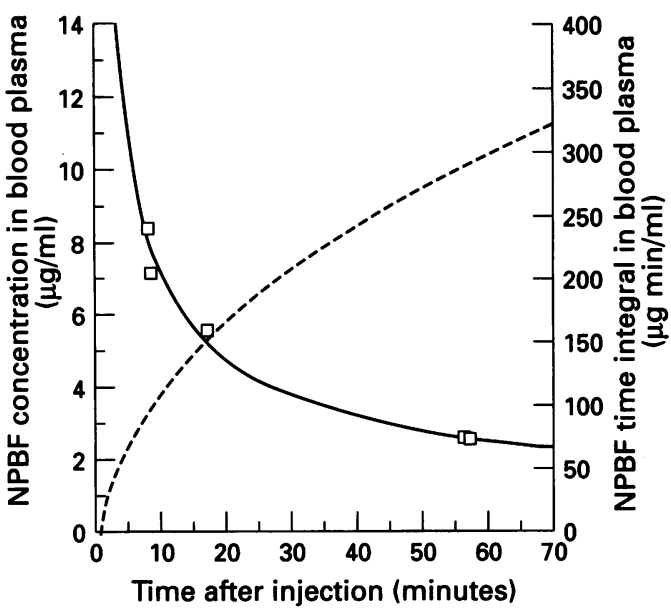

Figure 2 Example of the non-protein bound fluorescein (NPBF) concentration (solid line, left scale) and the time integral of NPBF concentration in blood plasma (broken line, right scale) as a function of the time after fluorescein injection. The squares represent the NPBF concentration values measured in the plasma samples. The curves represent equations (3) and (4) with $\alpha=27 \cdot 1$ and $\beta=0.580$.

(4) The peak anterior chamber fluorescence was determined from each measurement scan (Fig 1) and the corresponding mean autofluorescence value was subtracted.

(5) The diffusion coefficient $k_{d}$ was calculated for each measurement scan using equations (2) and (4).

(6) The mean value of $k_{d}$ measured at 30 and 40 minutes was calculated for each eye since these values did not differ significantly. ${ }^{23}$

All data processing was performed using software which was specially designed for the concerted action ('ANT SEGMENT BAB'). This program can be used off line, corrects for autofluorescence and light loss in the instrumental lens used, performs calculations of decay and time integral of NPBF in blood plasma, and calculates the mean value of $k_{d}$.

\section{EVALUATION}

The significance of differences in the values of diffusion coefficient and NPBF time integral among the different centres was evaluated with the non-parametric Kruskal-Wallis rank test with correction for tied ranks. A non-parametric multiple comparison test with corrections for tight values and unequal numbers of

Table 1 Data of participants

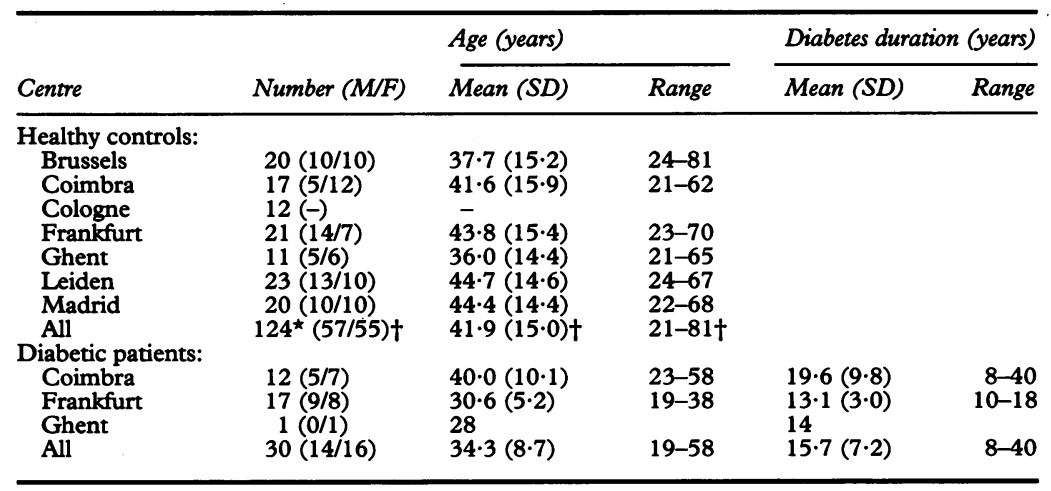

^All centres. †Excluding the Cologne centre. data in the groups was applied on each pair of groups. ${ }^{32}$ Non-parametric tests were required since some of the data were not normally distributed according to the D'Agostino test for normality. ${ }^{32}$

\section{Results}

SUBJECT DATA OF THE PARTICIPATING CENTRES The data of the healthy volunteers and diabetic patients of the different centres are given in Table 1. Sex and age data from the Cologne centre could not be obtained.

\section{FLUORESCEIN IN BLOOD PLASMA}

NPBF concentration and time integral values

The calculated mean value and SD of the NPBF concentration and time integral at 35 minutes after injection of fluorescein are given for each centre in Table 2 . The values were calculated with the use of equations (3) and (4). No significant differences in the time integral values between centres were found $(p \geqslant 0 \cdot 15)$ except between those of the Cologne centre and every other centre $(p<0.007)$ and between those of the Leiden and Coimbra centres $(p=0.043)$.

\section{Reproducibility}

The plasma NPBF time integral values at 35 minutes after injection measured at two different times with a mean interval of 3.06 (SD 2.0) (range $0 \cdot 7-8 \cdot 0$ ) months did not differ significantly (double sided Wilcoxon paired test $p=0 \cdot 46, n=57)$.

\section{Age dependency}

A low but significant correlation between age and plasma integral value at 35 minutes after injection was found for all healthy controls together (except Cologne): correlation coefficient $=0.25, p=0 \cdot 0086$. The mean increase in time integral value between 20 and 80 years amounted to $31 \%$ and the coefficient of relative variation was $41 \%$.

\section{Diabetic patients}

The plasma NPBF time integral values of all diabetic patients $(n=30)$ at 35 minutes after injection did not differ significantly from those of the healthy controls (all controls: $p=0.063$; all controls except those of Cologne: $p=0 \cdot 26$ ).

\section{INTRAOCULAR PRESSURE}

The IOP values of right and left eyes were correlated in each centre as well for healthy volunteers and for diabetic patients $(r>0.69$, $\mathrm{p}<0.002$ and $r>0.66, \mathrm{p}<0.019$, respectively). The mean IOP values of both eyes were 15.3 (SD 2.7) (range 9.5-22.5) $\mathrm{mm} \mathrm{Hg}$ and 15.7 (2.6) (range 10.3-20.0) $\mathrm{mm} \mathrm{Hg}$ for volunteers and patients, respectively. 
Table 2 Non-protein bound fluorescein in blood

\begin{tabular}{|c|c|c|c|c|}
\hline \multirow[b]{2}{*}{ Centre } & \multicolumn{2}{|c|}{ Concentration $\left(\mu g m l^{-1}\right)^{\star}$} & \multicolumn{2}{|c|}{ Time integral $\left(\mu g \min m^{-1}\right) \dagger$} \\
\hline & Mean (SD) & Range & Mean (SD) & Range \\
\hline \multicolumn{5}{|l|}{ Healthy controls: } \\
\hline Brussels & $4.85(1.07)$ & $3 \cdot 28-7 \cdot 41$ & $318(64)$ & $195-466$ \\
\hline Coimbra & $3.94(1.36)$ & $1 \cdot 50-6 \cdot 75$ & $242(63)$ & $98 \cdot 1-344$ \\
\hline Cologne & $7.39(2.01)$ & $3 \cdot 92-11 \cdot 4$ & $1930(1170)$ & $451-4090$ \\
\hline Frankfurt & $4.50(1.83)$ & $1.46-9 \cdot 33$ & $273(89)$ & $135-493$ \\
\hline Ghent & $3.74(0.60)$ & $2 \cdot 79-4 \cdot 83$ & $275(44)$ & $185-354$ \\
\hline Leiden & $5.06(1.22)$ & $2 \cdot 34-7 \cdot 60$ & $324(68)$ & $145-414$ \\
\hline Madrid & $4.06(1.69)$ & $1 \cdot 01-7 \cdot 28$ & $288(114)$ & $95 \cdot 6-499$ \\
\hline All & $4.73(1.74)$ & $1 \cdot 01-11 \cdot 4$ & $449(605)$ & $95 \cdot 6-4090$ \\
\hline All except Cologne & $4 \cdot 44(1.45)$ & $1 \cdot 01-9 \cdot 33$ & $290(83)$ & $95 \cdot 6-499$ \\
\hline \multicolumn{5}{|l|}{ Diabetic patients: } \\
\hline Coimbra & $3.64(1 \cdot 13)$ & $1.98-5.29$ & $243(44)$ & $186-311$ \\
\hline Frankfurt & $4.79(1.81)$ & $2 \cdot 53-10 \cdot 7$ & $311(94)$ & $183-589$ \\
\hline Ghent & $3 \cdot 20$ & & 190 & \\
\hline All & $4.28(1.63)$ & $1 \cdot 98-10 \cdot 7$ & $279(84)$ & $183-589$ \\
\hline
\end{tabular}

^NPBF concentration in blood 35 minutes after injection.

†Time integral of NPBF concentration in blood 35 minutes after injection.

\section{DIFFUSION COEFFICIENT THROUGH THE BLOOD-AQUEOUS BARRIER}

\section{Mean values}

The diffusion coefficient through the bloodaqueous barrier $\left(k_{d}\right)$ of each healthy control and patient is presented as a function of age in Figure 3. The mean value of both eyes was used because the values of right and left eyes were significantly correlated in each healthy control and patient group $(r>0.85, \mathrm{p}<0.0001$ except Madrid: $r=0.51, \mathrm{p}=0.023)$. The mean value, standard deviation, and total range of $k_{d}$ in each group are given in Table 3.

\section{Reproducibility}

The mean values and standard deviations of $k_{d}$ measured a second time and the corresponding interval times are presented in Table 4 for each of the four centres that repeated the measurements. The values did not differ significantly from the first ones (double sided Wilcoxon paired test $\mathrm{p}>0.39$ ).

\section{Differences between centres}

The significance of the differences in the values of $k_{d}$ between centres is presented in Table 5 . The values between pairs of centres were not different (Kruskal-Wallis test $\mathrm{p}>0.05$ ) except between Cologne and Frankfurt $(p=0 \cdot 012)$. No significant difference was found between the values of all diabetic patients and those of all healthy controls (Mann Whitney test $\mathrm{p}=0.061$; excluding Cologne: $\mathrm{p}=0.15$ ).

DIFFUSION COEFFICIENT VERSUS AGE OR SEX No significant correlation between age and diffusion coefficient was found in each of the centres Ghent, Leiden, and Coimbra $(r \leqslant 0.4$, $p \geqslant 0.09$ ) but a significant correlation was found in Brussels, Frankfurt, and Madrid $(r \geqslant 0.7, p \leqslant 0.0006)$. In all healthy controls together (except those of Cologne because of missing data) a small but significant correlation was found (increase between 20 and 80 years: factor $2 \cdot 2, r=0.54, p<0.0001$, Fig 3).

No significant differences were found between the values of $k_{d}$ of male and female healthy participants (mean values: $5 \cdot 15 \times 10^{-4}$ and $5.04 \times 10^{-4} \mathrm{miri}^{-1}$, respectively; MannWhitney test: $\mathrm{p}>0 \cdot 5$ ).

No significant correlation between $k_{d}$ and age was found in the individual diabetes groups $(r<0.2, \mathrm{p} \geqslant 0.47)$ nor in all diabetes patients together $(r=0 \cdot 15, \mathrm{p}=0 \cdot 43)$.

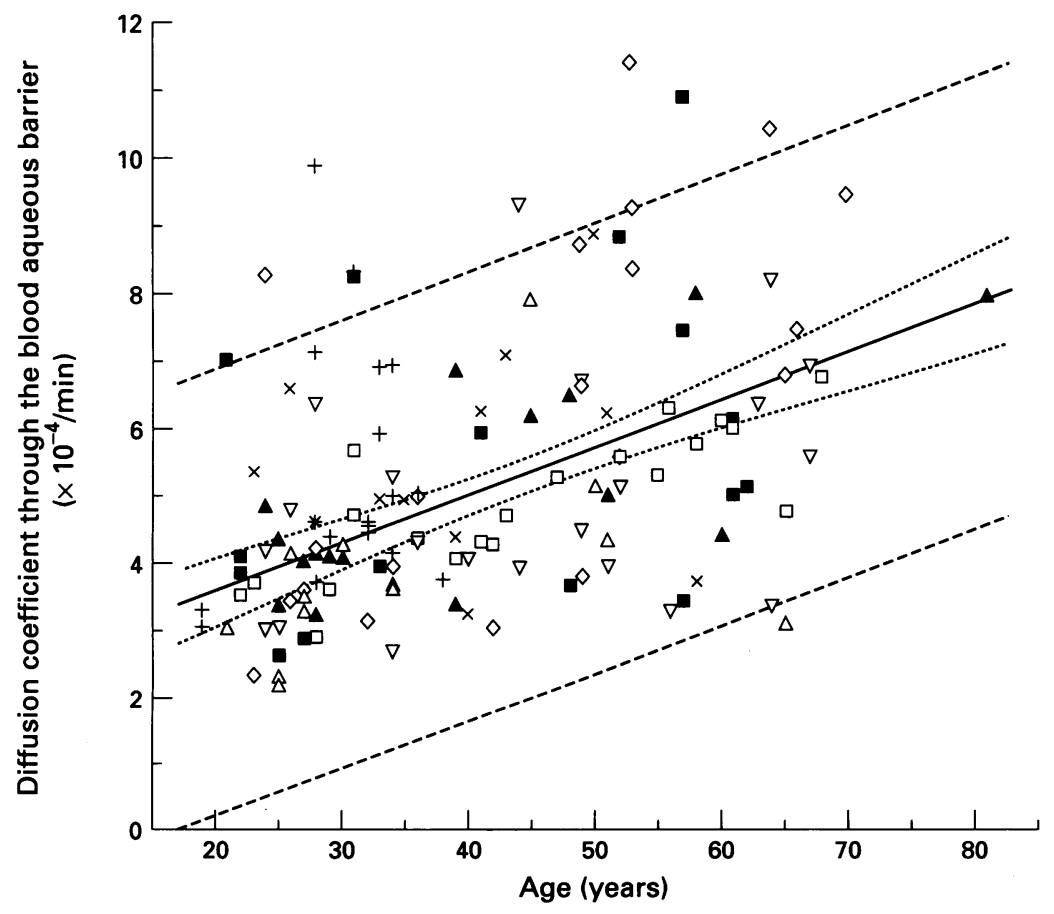

Figure 3 Diffusion coefficient through the blood-aqueous barrier as a function of age. The solid line was obtained using a linear regression procedure to the data points of the healthy controls in all centres except Cologne. The dotted lines represent the $95 \%$ probability intervals for the regression line and the broken lines the $95 \%$ probability intervals for the data points. Healthy controls: Brussels (solid triangles), Coimbra (solid squares),

Frankfurt (open diamonds), Ghent (open triangles), Leiden (inverted triangles), Madrid (open squares). Diabetic patients: Coimbra ( $\times)$, Frankfurt ( + ), and Ghent ( $\left.{ }^{\star}\right)$.

\section{DIFFUSION COEFFICIENT VERSUS DIABETES DURATION}

No significant correlation between $\mathrm{k}_{\mathrm{d}}$ and diabetes duration was found in the individual centres $(r \leqslant 0.21, \mathrm{p} \geqslant 0.49)$ nor in all patients together $(r=0 \cdot 13, \mathrm{p}=0.49)$.

\section{Discussion}

\section{GENERAL CONCLUSIONS}

The method presented is straightforward, highly evolved, and worked out in detail. It consists of an injection of fluorescein, the taking of three blood samples, and six fluorophotometric measurements per eye. After handling of the blood samples, the value of $k_{d}$ can be obtained in a few minutes by nonspecialised personnel with the sophisticated but easy to use software.

The diffusion coefficient $\left(k_{d}\right)$ through the blood-aqueous barrier was measured in each of the seven centres without problems in about 1 hour and 15 minutes. The results were found to be reliable and reproducible provided the protocol was strictly followed.

The utility of the method is obvious. It can be used when changes of the BAB function are suspected and a reliable quantitative outcome 
is required, such as in studies concerning the recovery time of the $\mathrm{BAB}$ function after medication or surgery or the effect of drugs and drug dosage on the barrier function. ${ }^{1-20}$

The Concerted Action study demonstrated the feasibility of international multicentre studies even if protocols and procedures are complex. Such studies are beneficial for future studies on ocular pathophysiology, especially in case of diseases occurring sporadically and for analysis of the effects of geographical differences on disease and treatment.

\section{SPECIFIC REMARKS}

The values of $k_{d}$ found in the seven centres had similar values and standard deviation (Table 3). No significant differences between the values of the various centres were found ( $p>0.05$, Table 5) except between Cologne and Frankfurt $(p=0.012)$. These results clearly demonstrate the reliability of the absolute values of $k_{d}$ obtained.

The reproducibility of the measurement of $k_{d}$ was assessed in four centres by repeating measurements after 1 to 8 months. No significant differences between the values of the first and second measurements were found in each of the centres (Wilcoxon paired test $\mathrm{p}>0.390$ ). These

Table 3 Diffusion coefficient through the blood-aqueous barrier

\begin{tabular}{|c|c|c|c|}
\hline Centre & $\begin{array}{l}\text { Number of } \\
\text { participants }\end{array}$ & $\begin{array}{l}\text { Mean }(S D)^{\star} \\
\left(\times 10^{-4} \min ^{-1}\right)\end{array}$ & $\begin{array}{l}\text { Range } \\
\left(\times 10^{-4} \min ^{-1}\right)\end{array}$ \\
\hline \multicolumn{4}{|l|}{ Healthy controls: } \\
\hline Brussels & 20 & $4.77(1.51)$ & $2 \cdot 88-7 \cdot 99$ \\
\hline Coimbra & 17 & $5.48(2.33)$ & $2 \cdot 62-10 \cdot 88$ \\
\hline Cologne & 12 & $3.47(2.09)$ & $1 \cdot 13-8 \cdot 49$ \\
\hline Frankfurt & 21 & $6.09(2.77)$ & $2 \cdot 33-11 \cdot 36$ \\
\hline Ghent & 11 & $3.85(1.59)$ & $2 \cdot 19-7 \cdot 90$ \\
\hline Leiden & 23 & $4.99(1.69)$ & $2 \cdot 71-9 \cdot 32$ \\
\hline Madrid & 20 & $4.87(1.05)$ & $2 \cdot 90-6 \cdot 75$ \\
\hline All centres & 124 & $4.94(2.04)$ & $1 \cdot 13-11 \cdot 36$ \\
\hline All centres except Cologne & 112 & $5 \cdot 10(1.98)$ & $2 \cdot 19-11 \cdot 36$ \\
\hline \multicolumn{4}{|l|}{ Diabetic patients: } \\
\hline Coimbra & 12 & $5.65(1.55)$ & $3 \cdot 24-8 \cdot 86$ \\
\hline Frankfurt & 17 & $5.35(1.89)$ & $3 \cdot 05-9 \cdot 87$ \\
\hline Ghent & 1 & $4 \cdot 60$ & \\
\hline All centres & 30 & $5.45(1.71)$ & $3 \cdot 05-9 \cdot 87$ \\
\hline
\end{tabular}

${ }^{\star}$ Mean value (SD) of $k_{d}$ (both eyes averaged).

Table 4 Reproducibility of the diffusion coefficient through the blood-aqueous barrier

\begin{tabular}{|c|c|c|c|c|c|}
\hline Centre & $\begin{array}{l}\text { Time interval } \\
\text { (months) }\end{array}$ & $\begin{array}{l}\text { No of } \\
\text { participants }\end{array}$ & $\begin{array}{l}\text { Mean }(S D) \dagger \\
\left(\times 10^{-4} \text { min }^{-1}\right)\end{array}$ & $\begin{array}{l}\text { Range } \\
\left(\times 10^{-4} \min ^{-1}\right)\end{array}$ & $\stackrel{p}{\text { Value } \ddagger}$ \\
\hline \multicolumn{6}{|c|}{ Healthy controls: } \\
\hline Brussels & $2 \cdot 1(1 \cdot 7)$ & 17 & $4.70(0.94)$ & $3 \cdot 24-6 \cdot 49$ & $>0.5$ \\
\hline Coimbra & $3.4(1.5)$ & 15 & $5 \cdot 78(2 \cdot 31)$ & $3 \cdot 73-13 \cdot 1$ & 0.39 \\
\hline Frankfurt & $4 \cdot 7(2 \cdot 1)$ & 15 & $6.04(3 \cdot 10)$ & $2 \cdot 45-13 \cdot 78$ & $>0.5$ \\
\hline Ghent & $1.3(0.4)$ & 8 & $3.68(2.36)$ & $1 \cdot 70-8 \cdot 96$ & $>0.5$ \\
\hline All centres & $3 \cdot 1(2 \cdot 0)$ & 55 & $5 \cdot 21(2 \cdot 36)$ & $1 \cdot 70-13 \cdot 78$ & $>0.5$ \\
\hline \multicolumn{6}{|c|}{ Diabetic patients: } \\
\hline Coimbra & $0.8(0.2)$ & 12 & $5 \cdot 37(1 \cdot 24)$ & $2 \cdot 94-7 \cdot 74$ & $>0.5$ \\
\hline
\end{tabular}

* Mean time (SD) between first and second measurements.

†Mean value (SD) of $k_{d}$ measured the second time (both eyes averaged).

$\ddagger$ Double sided $p$ value obtained with the Wilcoxon paired test for significance of the difference between the first and second measurements.

Table 5 Significance of differences in blood-aqueous barrier diffusion coefficient between centres

\begin{tabular}{lllllll}
\hline & Coimbra & Cologne & Frankfurt & Ghent & Leiden & Madrid \\
\hline Brussels & $>0.5$ & 0.37 & $>0.5$ & $>0.5$ & $>0.5$ & $>0.5$ \\
Coimbra & & 0.09 & $>0.5$ & $>0.5$ & $>0.5$ & $>0.5$ \\
Cologne & & & 0.012 & $>0.5$ & 0.12 & 0.082 \\
Frankfurt & & & & 0.16 & $>0.5$ & $>0.5$ \\
Ghent & & & & & $>0.5$ & $>0.5$ \\
Leiden & & & & & & $>0.5$
\end{tabular}

«Probability for equal values of the diffusion coefficient through the blood-aqueous barrier (double sided Kruskal-Wallis test). findings suggest that the methodologies described can be used for long term studies of $k_{d}$.

The mean value and standard deviation of $\mathrm{k}_{\mathrm{d}}\left(\times 10^{-4} \mathrm{~min}^{-1}\right)$ for healthy volunteers in this study (4.94 (2.04), $\mathrm{n}=24)$ correspond with values found in previous studies $(9 \cdot 7(4 \cdot 6)$, $\mathrm{n}=24^{25} ; 6 \cdot 8(3 \cdot 7), \mathrm{n}=20^{33} ; 6 \cdot 1(2 \cdot 7), \mathrm{n}=10^{24}$; $\left.4 \cdot 7(1 \cdot 5), \mathrm{n}=23^{23} ; 3 \cdot 7(0 \cdot 7), \mathrm{n}=15^{27}\right)$.

Care should be taken when using fluorophotometry for evaluating the BAB after an ocular lens extraction followed by implantation of an iris claw lens. The aqueous flow will be hindered by this lens and the fluorescein originating from the iris vessels will be forced to follow other ways out. This can result in a lower fluorescein concentration in the anterior chamber and a higher one in the posterior chamber or anterior vitreous, ${ }^{18}$ in comparison with an eye without such an implant lens. The concentration values at both sides of the implant lens should be taken into consideration for evaluation of the BAB permeability. The method presented takes only the anterior chamber into consideration, assuming that the fluorescein concentration at the posterior side of the lens is negligible.

\section{COMPARISON WITH THE LASER FLARE CELL} METER

The BAB function can be evaluated also with the laser flare cell meter (LFCM). The LFCM assesses the relative protein content in the anterior chamber by measurement of the intensity of scattered laser light. ${ }^{19}$ The measurement is rapid, simple, and non-invasive and is therefore of value for daily clinical practice, while the fluorescein injection and blood sample takings make fluorophotometry less applicable. ${ }^{28}$ The value of relative protein content is expressed in photon counts per millisecond and depends on the detection geometry of the instrument. Furthermore, this value depends on size and shape of the protein molecules in the anterior chamber. These features contrast with those of the diffusion coefficient $\mathrm{k}_{\mathrm{d}}$ as measured by fluorophotometry which provides a physical value for the leakage of small fluorescein molecules $(\mathrm{MW}=376)$ through the BAB. This makes fluorophotometry more sensitive in detecting early changes in BAB function. ${ }^{34} 35$ Note that the $k_{d}$ value is independent of aqueous flow ${ }^{23}$ while the LFCM measures a steady state value of protein contents which depends on aqueous flow. ${ }^{26}$

\section{PROBLEMS ENCOUNTERED}

The interval time between the first plasma sample and the fluorescein injection was critical. A time less than about 5 minutes resulted in an inaccurate time of sampling while the fluorescein concentration in plasma was changing rapidly and a time greater than about 9 minutes resulted in an inaccurate first part of the plasma time integral. In both cases the values of $k_{d}$ were unreliable. The data of five volunteers were rejected as a result of incorrect time of the first plasma sample. 
One centre (Cologne) demonstrated plasma time integral values largely deviating from the values of the other centres (factor 6.7; $\mathrm{p}<0.007)$. On the other hand the values of the diffusion coefficient through the BAB found at this centre did not differ significantly from the other centres except Frankfurt (Table 5). This contradiction may be explained by an incorrect calibration of the fluorophotometer in Cologne resulting in apparent excessive fluorescein concentration values in the plasma samples and in the anterior chamber; these errors cancel out in the calculation of the diffusion coefficient.

(One major problem encountered with the Concerted Action study was the time consuming communication between the hospitals in the different countries, mainly caused by language problems.) Concerted Action supported in part by the European
Commission, on 'Ocular Fluorometry: Standardization and Instrumentation Development' of the 4th European Community Medical and Health Research Programme (No MR 4*/0314/P)

The authors thank E Boets, $\mathrm{MD}, \mathrm{PhD}$ and Professor J A Oosterhuis for critically reading the manuscript.

1 Sawa M, Araie M, Tanishima T. A fluorophotometric study of the barrier functions in the anterior segment of the eye after intracapsular cataract extraction. fpn $\mathcal{f}$ Ophthalmo 1983; 27: 404-15.

2 Miyake K, Asakura M, Maekubo K. Consensual reactions of human blood-aqueous barrier to implant operations. Arch Ophthalmol 1984; 102: 558-61.

3 Sawa M, Sakanishi Y, Okuno Y, Shimizu H. Posterior chamber lens implantation and anterior segment barrier function: a fluorophotometric study. $f_{p n} ¥$ Ophthalmol 1988; 32: 297-303.

4 Smith RT, Campbell CJ, Koester CJ, Trokel S, Anderson A. The barrier function in extracapsular cataract surgery. Ophthalmology 1990; 97: 90-5.

5 Ferguson VM, Spalton DJ. Recovery of the blood-aqueous barrier after cataract surgery. $\mathrm{Br} \mathcal{F}$ Ophthalmol 1991; 75: 106-10.

6 Diestelhorst M, Aspacher F, Konen W, Krieglstein GK, Hilgers RD. Effect of dexamethasone $0.1 \%$ and prednisolone acetate $1.0 \%$ eye drops on the blood-aqueous barrier after cataract surgery: a controlled randomized fluorophotometric study. Graefes Arch Clin Exp Ophthalmol 1992; 230: 451-3.

7 Ferguson VM, Spalton DJ. Continued breakdown of the blood aqueous barrier following cataract surgery. $\mathrm{Br} f$ Ophthalmol 1992; 76: 453-6.

8 Benitez del Castillo JM, Hernandez JL, Iradier MT, Del Rio MT, Garcia Sanchez J. Fluorophotometry in phakic eyes with anterior chamber intraocular lens implantation to correct myopia. I Cataract Refract Surg 1993; 19: 607-9.

9 Flach AJ, Graham J, Kruger LP, Stegman RC, Tanenbaum L. Quantitative assessment of postsurgical breakdown of the blood-aqueous barrier following administration of $0.5 \%$ ketorolac tromethamine solution. A double-masked $0.5 \%$ ketorolac tromethamine solution. A double-masked, paired comparison

10 Flach AJ, Kraff MC, Sanders DR, Tanenbaum L. The quantitative effect of $0.5 \%$ ketorolac tromethamine solution and $0.1 \%$ dexamethasone sodium phosphate solution on postsurgical blood-aqueous barrier. Arch Ophthalmo 1988; 106: 480-3.

11 Kraff MC, Sanders DR, McGuigan L, Raanan MG. Inhibition of blood-aqueous humor barrier breakdown with diclofenac. A fluorophotometric study. Arch with diclofenac. A fluoroph

12 Krupin T, Waltman SR. Fluorophotometry in juvenileonset diabetes: long-term follow-up. Fpn $\mathcal{F}$ Ophthalmo 1985; 29: 139-45.
13 Boot JP, van Gerven JM, van Best JA, Vrij L, Lemkes HH, Oosterhuis JA. Blood retinal and blood aqueous barriers in diabetics by fluorophotometry. Doc Ophthalmol 1989 71: 19-27.

14 van Wirdum E, van Best JA, Bruining GJ, de Beaufort C, Oosterhuis JA. Blood-retinal and blood-aqueous barrier permeability, lens autofluorescence and transmission in insulin-dependent diabetic youngsters. Graefes Arch Clin Exp Ophthalmol 1989; 227: 26-9.

15 Schalnus R, Ohrloff C, Jungmann E, Maass K, Rinke S Wagner A. Permeability of the blood-retinal barrier and the blood-aqueous barrier in type I diabetes withou diabetic retinopathy: simultaneous evaluation with fluorophotometry. Ger f Ophthalmol 1993; 2: 202-6.

16 Yoshida A, Ishiko S, Kojima M, Ogasawara H. Permeability of the blood-ocular barrier in adolescent and adult diabetic patients. Br $\mathcal{F}$ Ophthalmol 1993; 77: 158-61.

17 Feamley IR, Spalton DJ, Smith SE. Anterior segment fluorophotometry in acute anterior uveitis. Arch Ophthalmol 1987; 105: 1550-5.

18 Ferguson VM, Spalton DJ. Quantification of the ocular response to treatment in posterior uveitis. Acta Ophthalmo 1992; 70: 824-31.

19 Miyake K, Miyake T, Kayazawa F. Blood-aqueous barrie in eyes with retinal vein occlusion. Ophthalmology 1992; 99: 906-10.

20 Little BC, Ambrose VM. Blood-aqueous barrier breakdown associated with rhegmatogenous retinal detachment. Eye 1991; 5: 56-62.

21 Boot JP, van Best JA, Tjin A Tsoi EWSJ, Kappelhof JP, Oosterhuis JA. Plasma fluorescein decay determination during fluorophotometry. Doc Ophthalmol 1987; 65 403-22.

22 Kappelhof JP, van Best JA, van Valenberg PLJ, Oosterhuis JA. Inward permeability of the blood-retinal barrier by fluorophotometry. Invest Ophthalmol Vis Sci 1987; 28. 665-71.

23 Van Best JA, Kappelhof JP, Laterveer L, Oosterhuis JA. Blood aqueous barrier permeability versus age by fluorophotometry. Curr Eye Res 1987; 6: 855-63.

24 McLaren JW, Brubaker RF. Measurement of fluorescein and fluorescein monoglucuronide in the living human eye. Invest Ophthalmol Vis Sci 1986; 27: 966-74.

25 Nagataki S. Aqueous humor dynamics of human eyes as studied using fluorescein. $\mathscr{f} p n \mathcal{F}$ Ophthalmol 1975; 19 235-49.

26 Oshika T, Sakurai M, Araie M. A study on diurnal fluctuation of blood-aqueous barrier permeability to plasma proteins. Exp Eye Res 1993; 56: 129-33.

27 Schalnus $R$, Ohrloff $C$. The blood-retina barrier and bloodaqueous humor barrier in type I diabetic patients without retinopathy. Determination of permeability using fluorophotometry and laser flare measurements (in German). Klin Monatsbl Augenheilkd 1993; 202: 281-7.

28 Shah SM, Spalton DJ, Allen RJ, Smith SE. A comparison of the laser flare cell meter and fluorophotometry in assessment of the blood-aqueous barrier. Invest Ophthalmol Vis Sci 1993; 34: 3124-30.

29 Van Best JA, Mota MC, Larsen M. Protocols approved within the framework of a Concerted Action of the European Community Biomedical Programme on Ocular Fluorometry (1989-1992). In: Cunha-Vaz JG, Leite E Ramos MC, eds. Manual of ocular fuorometry. Coimbra, Portugal: Execução Gráfica, GC-Gráfica de Coimbra, Portugal: Execução

30 Grotte D, Mattox V, Brubaker R. Fluorescent, physiological and pharmacokinetic properties of fluorescein glucuronide. Exp Eye Res 1985; 40: 23-33.

31 Van Best JA, Diestelhorst $M$, Leite E, Fantaguzzi S, Schalnus $\mathbf{R}$. Corneal endothelial permeability and aqueous flow using a standard protocol. Graefes Arch Clin Exp Ophthalmol 1995; 233: 582-91.

32 Zar JH. In: Kurtz B, ed. Biostatistical analysis. 2nd ed. Englewood Cliffs, NJ: Prentice-Hall International Editions, 1984: 95-6 and 162-201.

33 Araie M, Sawa M, Nagataki S, Mishima S. Aqueous humor dynamics in man as studied by oral fluorescein. $f_{p} n$ Ophthalmol 1980; 24: 346-62.

34 Schalnus R, Ohrloff C. The blood-retina barrier and bloodaqueous humor barrier in type I diabetic patients without retinopathy. Determination of permeability using fluorophotometry and laser flare measurements (in German). photometry and laser flare measurements

35 Schalnus $R$, Ohrloff $C$. Quantification of blood-aqueou barrier function using laser flare measurement and fluorophotometry - a comparative study. Lens Eye Toxic Re 1992; 9: 309-20. 